\title{
Social inequality and perinatal health: comparison of three Brazilian cohorts
}

F. Lamy Filho ${ }^{1}$ A.N. Assunção Júnior ${ }^{2}$, A.A.M. Silva ${ }^{2}$, Z.C. Lamy ${ }^{3}$, M.A. Barbieri ${ }^{4}$ and H. Bettiol ${ }^{4}$

\author{
${ }^{1}$ Departamento de Medicina III, ${ }^{2}$ Departamento de Saúde Pública, \\ ${ }^{3}$ Hospital Universitário, Universidade Federal do Maranhão, São Luís, MA, Brasil \\ ${ }^{4}$ Departamento de Pediatria, Faculdade de Medicina de Ribeirão Preto, \\ Universidade de São Paulo, Ribeirão Preto, SP, Brasil
}

\section{Correspondence}

A.A.M. Silva

Departamento de Saúde Pública UFMA

Rua Barão de Itapary, 155 65070-020 São Luís, MA

Brasil

Fax: +55-98-3232-1264

E-mail: aasilva@elo.com.br

Research supported by CNPq (Nos. 523474/96-2 and 520664/98-1) and FAPESP (Nos. 93/0525-0 and 00/09508-7).

Received October 10, 2006 Accepted May 21, 2007 .................

\begin{abstract}
The objective of the present study was to estimate and compare social inequality in terms of three indicators, i.e., low birth weight (LBW), preterm birth (PTB) and small for gestational age (SGA) birth, in three birth cohorts. Two cohorts were from the city of Ribeirão Preto, where data were collected for all 6748 live born singletons in 1978/79 and for one third of live born singletons (2846) in 1994. The third cohort consisted of 2443 singletons born in São Luís over a period of one year (1997/98). In Ribeirão Preto, LBW and PTB rates increased in all social strata from 1978/79 to 1994. Social inequalities regarding LBW and PTB disappeared since the increase in these rates was more accelerated in the groups with higher educational level. The percentage of SGA infants increased over the study period. Social inequality regarding SGA birth increased due to a more intense increase in SGA births in the strata with lower schooling. In São Luís, in 1997/98 there was no social inequality in LBW or PTB rates, whereas SGA birth rate was higher in mothers with less schooling. We speculate that the more accelerated increase in medical intervention, especially due to the increase in cesarean sections in the more privileged groups, could be the main factor explaining the unexpected increase in LBW and PTB rates in Ribeirão Preto and the decrease or disappearance of social inequality regarding these perinatal indicators in the two cities.
\end{abstract}

Key words

- Low birth weight

- Preterm birth

- Small for gestational age

birth

- Socioeconomic factors

- Risk factors

\section{Introduction}

The great health inequalities detected between the rich and the poor are particularly visible among newborns and infants (1). Inequality in perinatal health has been well documented in the literature. Families with lower schooling and income have higher rates of low birth weight (LBW), preterm birth (PTB), intrauterine growth restriction
(IUGR), and infant mortality (2-5). However, few studies are available about the assessment of the evolution of social inequality along time. In Sweden and in the United Kingdom, for example, social inequality regarding LBW is stable (6-9), whereas in the Czech Republic it is increasing due to a more accelerated increase in LBW rate among infants born to mothers with lower schooling $(6,10)$. In Porto Ale- 
gre, Brazil, social inequality regarding infant mortality has recently decreased due to a more accelerated reduction in the infant mortality rate among children born to mothers with lower schooling (11).

Two processes, separately or in combination, can cause an infant to be born with lower than normal weight: a reduction of the duration of gestation (PTB) and IUGR. These events can be represented by two indicators of perinatal health, i.e., PTB and small for gestational age (SGA) birth, respectively (4). Thus, in order to understand these phenomena it is important to study not only LBW, but also PTB and SGA rates. Since these are distinct phenomena, social inequality may occur and evolve differently among preterm infants and infants with IUGR.

In Brazil, few studies are available regarding whether perinatal social inequalities are increasing, are remaining stable or are decreasing (12-14). There is also little information about regional differences in these indicators (15).

The objective of the present study was to estimate and compare social inequality regarding three indicators of perinatal health, PTB, SGA and LBW, in three birth cohorts. Two of them, separated by a period of 15 years, were from the same city, Ribeirão Preto, located in a richer region of the Brazilian Southeast, while the third was from São Luís, located in a poorer region in the Northeast. This permitted us to assess whether social inequality in perinatal indicators occurs in a similar or in a different manner in two cities in two Brazilian regions and to evaluate whether social inequality regarding perinatal health is increasing, is remaining stable or is decreasing in the city of Ribeirão Preto.

\section{Material and Methods}

\section{Population studies}

Population studies were performed in two cities located in two different regions of Brazil (São Luís in the Northeast and Ribeirão Preto in the Southeast) in the 1970 and 1990 decades. In Ribeirão Preto, from June 1978 to May 1979, 6748 live born singletons were included in the analysis and 2846 were studied from April to August 1994. After the exclusion of records with missing birth weight the final sample size for analysis was 6747 for the first and 2839 for the second cohort. The option to study a 4-month period was due to the fact that no seasonality was observed in the distribution of births or of LBW or PTB rates in the 1978/79 study (16).

The data for the São Luís cohort were obtained by a systematic sampling of deliveries stratified per maternity. One every seven births was systematically selected in each hospital from birth listings. The study was started in March 1997 and ended in February 1998 , covering a period of one year, for a total of 2443 live born singletons from families residing in the municipality. After the exclusion of records with missing birth weight the final sample size for analysis was 2439. In 1996, hospital births represented $96.3 \%(95 \% \mathrm{CI}=94.1-98.6 \%)$ of all births, guaranteeing the representativity of the hospital birth sampling (17). The study was conducted at 10 public network units and at units covered by insurance plans and/or private units during the period from March 1, 1997 to February 28, 1998. The maternities where less than 100 deliveries occurred in 1996 and which attended only $2.2 \%$ of the deliveries of that year were excluded from the sample. Thus, the study is representative of $94 \%$ of the births that occurred during the study period.

A standardized questionnaire was used in the three studies, with small differences between them. The methodology was approximately the same and the details have been published in previous papers (18-20). The losses were low, i.e., 2.5 and $3.2 \%$ in Ribeirão Preto for the 1978/79 and 1994 cohorts, respectively, and 5.8\% in São Luís. 


\section{Study areas}

The city of Ribeirão Preto is located in the Northeast region of the State of São Paulo. In 1994 the population was 461,427 inhabitants, a $44.9 \%$ increase in relation to $1978 / 79$. This is one of the most developed cities in the country, with $99 \%$ of the residences having piped water and being served by the sewage network, and having one of the highest per capita incomes in the country, approximately US\$5,800 per year. The main economic activity of the city is the sugar cane industry, in addition to commerce and services. It is also a renowned regional university center. In 1978/79, the city had eight maternities and in 1994 it had ten (18). Its human development index was 0.855 in 2000, occupying 6th place in the São Paulo ranking and 22nd place in the national ranking (21).

The city of São Luís, the capital of the State of Maranhão, is located on an island along the northern coast of the state. In 1996 it had a population of 781,068 inhabitants. The city is located in one of the poorest regions in the country, where only $50 \%$ of the residences are connected to the sewage network and only $75 \%$ receive piped water. Its economic activity is based on the aluminum metal industry, on the export of mineral ore from the Carajás mountains and on the state production of soy, in addition to commerce and services. In 1997, São Luís had 18 maternities (19). Its human development index was 0.778 in 2000, occupying first place in the Maranhão ranking, but 1112th place in the national ranking. The per capita income of Ribeirão Preto was twice as high as that of São Luís in 2000 (21).

\section{Variables}

Three indicators of perinatal health were evaluated: LBW, PTB and SGA birth. Birth weight was categorized as low $(<2500 \mathrm{~g})$ and not low ( $\geq 2500 \mathrm{~g})$. A newborn was classified as preterm when its gestational age was less than 37 weeks as determined on the basis of the last normal menstrual period. Weight classification according to gestational age was based on the curve of Williams et al. (22). This curve shows intrauterine standards of growth and classifies newborns into three categories: adequate for gestational age large for gestational age and SGA. Infants whose weight was below the 10th percentile of this curve were classified as SGA, used as a proxy for IUGR. Infants whose birth weight was incompatible with the date of the last normal menstrual period or whose gestational age was implausible were recoded as "missing". Since missing gestational age data amounted to $25 \%$ in $1978 / 79$ and to $21.2 \%$ in 1994 for Ribeirão Preto and to $10.7 \%$ for São Luís, all cases with missing gestational age were imputed in a regression model. The characteristics used to impute gestational age were birth weight, parity, family income, and newborn infant sex (19).

The following variables available in the two databases were studied to determine the variation of the indicators of perinatal health according to socioeconomic characteristics: family income, maternal schooling, occupation of the head of the family, paternal schooling, and marital status of the mother.

\section{Statistical analysis}

Data were analyzed by the chi-square test for comparison of proportions. The relative risk and its $95 \%$ confidence interval were calculated to determine the effect of each variable on the indicators of perinatal health. The level of significance was set at $5 \%$ in all analyses $(\mathrm{P}<0.05)$.

\section{Results}

All perinatal indicator rates increased significantly in Ribeirão Preto from 1978/79 to 1994. The LBW rate increased from 7.2 to $10.7 \%$, the SGA rate from 10.6 to $12.5 \%$ and 
the PTB rate from 7.5 to $12.8 \%$. Compared to the Ribeirão Preto cohort, in São Luís, the LBW rate was lower $(7.6 \%)$ and the PTB $(12.7 \%)$ and SGA (13.3\%) rates were equal (Table 1).

Table 2 shows that during both periods studied in Ribeirão Preto the LBW rate was lower among infants from families with higher income, with higher parental schooling, with married mothers, and whose family heads had a more skilled occupation. A decrease in the relative risk of LBW was observed along the 15-year period according to all socioeconomic variables used. Regarding LBW, no association with any socioeconomic variable was detected in the São Luís cohort.

Table 3 shows that, in Ribeirão Preto, the risk for PTB was lower for the strata of less favorable socioeconomic conditions only in $1978 / 79$, with all variables showing $\mathrm{P}<$ 0.05, whereas in 1994 the association of socioeconomic variables with PTB disappeared. In 1994, only marital status was significantly associated with PTB $(\mathrm{P}=0.021)$, with the risk for the "cohabiting" category being $34 \%$ higher $(1.34,95 \% \mathrm{CI}=1.08$ 1.66) than for the "married" category. In São Luís, only family income was significantly associated with PTB (P=0.01), being 32\%

Table 1. Low birth weight, small for gestational age and preterm birth rates in the cities of Ribeirão Preto (1978/79 and 1994) and São Luís (1997/98).

\begin{tabular}{lcrc}
\hline Indicators & $\begin{array}{c}\text { Ribeirão Preto } \\
(1978 / 79)\end{array}$ & $\begin{array}{c}\text { Ribeirão Preto } \\
(1994)\end{array}$ & $\begin{array}{c}\text { São Luís } \\
(1997 / 98)\end{array}$ \\
\hline $\begin{array}{l}\text { Low birth weight } \\
\text { Yes }\end{array}$ & $486(7.2 \%)$ & $303(10.7 \%)$ & $186(7.6 \%)$ \\
$\quad$ No & $6261(92.8 \%)$ & $2536(89.3 \%)$ & $2253(92.4 \%)$ \\
Small for gestational age & & $* *$ & NS \\
$\quad$ Yes & $716(10.6 \%)$ & $354(12.5 \%)$ & $324(13.3 \%)$ \\
No & $6031(89.4 \%)$ & $2485(87.5 \%)$ & $2115(86.7 \%)$ \\
Preterm birth & & $*$ & NS \\
Yes & $503(7.5 \%)$ & $363(12.8 \%)$ & $309(12.7 \%)$ \\
No & $6244(92.5 \%)$ & $2476(87.2 \%)$ & $2130(87.3 \%)$ \\
\end{tabular}

Data are reported as number with percent in parentheses.

${ }^{*} \mathrm{P}<0.001$ compared to Ribeirão Preto (1978/79; chi-square test); ${ }^{* \star} \mathrm{P}<0.01 \mathrm{com}$ pared to Ribeirão Preto (1978/79; chi-square test); ${ }^{* * *} P<0.001$ compared to Ribeirão Preto (1994; chi-square test). NS = not significant compared to Ribeirão Preto (1994). lower $(0.68$; $95 \% \mathrm{CI}: 0.51-0.91)$ in the stratum with intermediate family income (1 to 3 minimum wages) than in the wealthier or poorer strata. Marital status was marginally associated with the PTB rate $(\mathrm{P}=0.075)$. Mothers without a companion were at greater risk of delivering preterm.

Table 4 shows that all socioeconomic variables were significantly associated with SGA births in the two Ribeirão Preto cohorts. From 1978/79 to 1994, social inequality regarding the risk of SGA births was reduced when measured by occupation or by family income but was increased when measured by maternal or paternal schooling. The risk of being born SGA according to marital status practically remained unchanged. In São Luís, this risk was higher for the poorer strata and for mothers with schooling of one to four years.

\section{Discussion}

Social inequality in low birth weight and its evolution in Ribeirão Preto

In Ribeirão Preto, LBW increased in all social strata from $1978 / 79$ to 1994 . The social inequalities regarding LBW were reduced since the increase in LBW was more marked in the wealthier and better educated groups. The results of the present study differ from others showing that social inequality regarding birth weight is stable, as reported for Sweden (6) and the United Kingdom (10), or increased, as reported for the Czech Republic (9).

The PTB rate also increased in all social groups. Social inequality regarding PTBs disappeared due to a more intense increase in PTB among the wealthier and better educated strata. The percentage of SGA newborns increased during the study period. Social inequality regarding SGA infants was reduced due to a more intense increase among the strata with lower schooling.

Although there was an increase in all 
Table 2. Low birth weight (LBW) rate according to socioeconomic variables in three Brazilian birth cohorts [Ribeirão Preto (1978/79), Ribeirão Preto (1994), São Luís (1997/98)].

\begin{tabular}{|c|c|c|c|c|c|c|c|c|c|}
\hline \multirow[t]{2}{*}{ Variables $^{a}$} & \multicolumn{3}{|c|}{ Ribeirão Preto (1978/79) } & \multicolumn{3}{|c|}{ Ribeirão Preto (1994) } & \multicolumn{3}{|c|}{ São Luís (1997/98) } \\
\hline & $\mathrm{N}$ & \%LBW & $\mathrm{RR}(95 \% \mathrm{Cl})$ & $\mathrm{N}$ & \%LBW & $\mathrm{RR}(95 \% \mathrm{Cl})$ & $\mathrm{N}$ & \%LBW & $\mathrm{RR}(95 \% \mathrm{Cl})$ \\
\hline Paternal schooling (years) & & & * & & & $\star * *$ & & & NS \\
\hline$\geq 12$ & 853 & $2.98 \%$ & 1.00 & 333 & $6.91 \%$ & 1.00 & 163 & $7.36 \%$ & 1.00 \\
\hline 9 to 11 & 667 & $4.58 \%$ & $\begin{array}{c}1.54 \\
(0.91-2.59)\end{array}$ & 595 & $9.08 \%$ & $\begin{array}{c}1.31 \\
(0.82-2.10)\end{array}$ & 835 & $6.83 \%$ & $\begin{array}{c}0.93 \\
(0.51-1.69)\end{array}$ \\
\hline 5 to 8 & 1382 & $6.76 \%$ & $\begin{array}{c}2.27 \\
(1.47-3.50)\end{array}$ & 891 & $10.66 \%$ & $\begin{array}{c}1.54 \\
(1.00-2.39)\end{array}$ & 724 & $7.60 \%$ & $\begin{array}{c}1.03 \\
(0.57-1.88)\end{array}$ \\
\hline 0 to 4 & 2766 & $7.56 \%$ & $\begin{array}{c}2.54 \\
(1.69-3.81)\end{array}$ & 542 & $13.47 \%$ & $\begin{array}{c}1.95 \\
(1.22-3.00)\end{array}$ & 331 & $10.27 \%$ & $\begin{array}{c}1.40 \\
(0.74-2.62)\end{array}$ \\
\hline Maternal schooling (years) & & & * & & & ** & & & NS \\
\hline$\geq 12$ & 660 & $2.30 \%$ & 1.00 & 368 & $7.88 \%$ & 1.00 & 119 & $3.36 \%$ & 1.00 \\
\hline 9 to 11 & 880 & $4.61 \%$ & $\begin{array}{c}2.00 \\
(1.12-3.59)\end{array}$ & 610 & $9.51 \%$ & $\begin{array}{c}1.21 \\
(0.79-1.85)\end{array}$ & 861 & $7.32 \%$ & $\begin{array}{c}2.18 \\
(0.81-5.87)\end{array}$ \\
\hline 5 to 8 & 1658 & $6.57 \%$ & $\begin{array}{c}2.86 \\
(1.68-4.86)\end{array}$ & 1039 & $10.20 \%$ & $\begin{array}{c}1.29 \\
(0.87-1.92)\end{array}$ & 1035 & $8.31 \%$ & $\begin{array}{c}2.47 \\
(0.92-6.62)\end{array}$ \\
\hline 0 to 4 & 3350 & $8.68 \%$ & $\begin{array}{c}3.77 \\
(2.26-6.30)\end{array}$ & 631 & $14.74 \%$ & $\begin{array}{c}1.87 \\
(1.26-2.78)\end{array}$ & 418 & $7.89 \%$ & $\begin{array}{c}2.35 \\
(0.85-6.50)\end{array}$ \\
\hline Occupation & & & * & & & $\star * *$ & & & NS \\
\hline Non-manual & 1090 & $3.21 \%$ & 1.00 & 587 & $8.18 \%$ & 1.00 & 502 & $6.77 \%$ & 1.00 \\
\hline Manual skilled/semiskilled & 3840 & $7.29 \%$ & $\begin{array}{c}2.27 \\
(1.60-3.23)\end{array}$ & 1587 & $10.78 \%$ & $\begin{array}{c}1.32 \\
(0.97-1.79)\end{array}$ & 1101 & $7.99 \%$ & $\begin{array}{c}1.18 \\
(0.81-1.73)\end{array}$ \\
\hline Manual unskilled & 1609 & $9.82 \%$ & $\begin{array}{c}3.06 \\
(2.12-4.41)\end{array}$ & 527 & $13.09 \%$ & $\begin{array}{c}1.60 \\
(1.13-2.27)\end{array}$ & 770 & $7.40 \%$ & $\begin{array}{c}1.09 \\
(0.73-1.65)\end{array}$ \\
\hline Marital status & & & * & & & * & & & NS \\
\hline Married & 5552 & $6.22 \%$ & 1.00 & 1675 & $9.01 \%$ & 1.00 & 704 & $6.39 \%$ & 1.00 \\
\hline Cohabiting & 661 & $10.89 \%$ & $\begin{array}{c}1.75 \\
(1.38-2.23)\end{array}$ & 700 & $13.00 \%$ & $\begin{array}{c}1.44 \\
(1.13-1.84)\end{array}$ & 1143 & $8.14 \%$ & $\begin{array}{c}1.27 \\
(0.90-1.79)\end{array}$ \\
\hline No companion & 459 & $13.47 \%$ & $\begin{array}{c}2.16 \\
(1.68-2.79)\end{array}$ & 346 & $15.03 \%$ & $\begin{array}{c}1.67 \\
(1.24-2.23)\end{array}$ & 591 & $8.12 \%$ & $\begin{array}{c}1.27 \\
(0.86-1.88)\end{array}$ \\
\hline \multicolumn{3}{|c|}{ Family income (in minimum wages) } & * & & & ** & & & NS \\
\hline$>3$ & 2162 & $3.98 \%$ & 1.00 & 1179 & $8.14 \%$ & 1.00 & 772 & $7.38 \%$ & 1.00 \\
\hline$>1$ to 3 & 2021 & $7.38 \%$ & $\begin{array}{c}1.85 \\
(1.43-2.40)\end{array}$ & 593 & $12.65 \%$ & $\begin{array}{c}1.55 \\
(1.17-2.07)\end{array}$ & 718 & $5.99 \%$ & $\begin{array}{c}0.81 \\
(0.55-1.19)\end{array}$ \\
\hline Up to 1 & 1242 & $9.12 \%$ & $\begin{array}{c}2.29 \\
(1.75-3.01)\end{array}$ & 237 & $13.08 \%$ & $\begin{array}{c}1.61 \\
(1.10-2.35)\end{array}$ & 786 & $8.52 \%$ & $\begin{array}{c}1.15 \\
(0.82-1.62)\end{array}$ \\
\hline Missing & 1322 & $10.39 \%$ & $\begin{array}{c}2.61 \\
(2.01-3.39)\end{array}$ & 830 & $12.17 \%$ & $\begin{array}{c}1.49 \\
(1.15-1.95)\end{array}$ & 163 & $11.66 \%$ & $\begin{array}{c}1.58 \\
(0.97-2.58)\end{array}$ \\
\hline
\end{tabular}

aTotals for some variables may differ because of missing values. $\mathrm{RR}=$ relative risk; $95 \% \mathrm{Cl}=$ confidence interval at $95 \%$.

${ }^{\star} \mathrm{P}<0.001,{ }^{\star \star} \mathrm{P}<0.01$, and ${ }^{\star \star *} \mathrm{P}<0.05$ for the likelihood ratio test. NS $=$ not significant. 
Table 3. Preterm birth (PTB) rate according to socioeconomic variables in three Brazilian birth cohorts [Ribeirão Preto (1978/79), Ribeirão Preto (1994), São Luís (1997/98)].

\begin{tabular}{|c|c|c|c|c|c|c|c|c|c|}
\hline \multirow[t]{2}{*}{ Variablesa } & \multicolumn{3}{|c|}{ Ribeirão Preto (1978/79) } & \multicolumn{3}{|c|}{ Ribeirão Preto (1994) } & \multicolumn{3}{|c|}{ São Luís (1997/98) } \\
\hline & $\mathrm{N}$ & \%РTB & $\mathrm{RR}(95 \% \mathrm{Cl})$ & $\mathrm{N}$ & \%РТВ & $\mathrm{RR}(95 \% \mathrm{Cl})$ & $\mathrm{N}$ & \%РTB & $\mathrm{RR}(95 \% \mathrm{Cl})$ \\
\hline Paternal schooling (years) & & & * & & & NS & & & NS \\
\hline$\geq 12$ & 853 & $3.45 \%$ & 1.00 & 333 & $9.88 \%$ & 1.00 & 163 & $14.11 \%$ & 1.00 \\
\hline 9 to 11 & 667 & $5.33 \%$ & $1.54(0.95-2.50)$ & 595 & $11.56 \%$ & $1.17(0.79-1.73)$ & 835 & $12.08 \%$ & $0.86(0.56-1.30)$ \\
\hline 5 to 8 & 1382 & $7.92 \%$ & $2.29(1.54-3.42)$ & 891 & $14.08 \%$ & $1.51(1.05-2.16)$ & 724 & $12.55 \%$ & $0.89(0.58-1.36)$ \\
\hline 0 to 4 & 2766 & $7.29 \%$ & $2.11(1.44-3.09)$ & 542 & $13.65 \%$ & $1.38(0.94-2.03)$ & 331 & $12.05 \%$ & $0.85(0.53-1.38)$ \\
\hline Maternal schooling (years) & & & * & & & NS & & & NS \\
\hline$\geq 12$ & 660 & $3.22 \%$ & 1.00 & 368 & $10.57 \%$ & 1.00 & 119 & $10.08 \%$ & 1.00 \\
\hline 9 to 11 & 880 & $4.72 \%$ & $1.47(0.88-2.46)$ & 610 & $13.42 \%$ & $1.27(0.89-1.82)$ & 861 & $11.72 \%$ & $1.16(0.66-2.05)$ \\
\hline 5 to 8 & 1658 & $7.20 \%$ & $2.24(1.42-3.52)$ & 1039 & $13.45 \%$ & $1.27(0.91-1.78)$ & 1035 & $13.90 \%$ & $1.38(0.79-2.41)$ \\
\hline 0 to 4 & 3350 & $8.49 \%$ & $2.64(1.71-4.07)$ & 631 & $13.59 \%$ & $1.29(0.90-1.84)$ & 418 & $12.14 \%$ & $1.20(0.66-2.18)$ \\
\hline Occupation & & & ** & & & NS & & & NS \\
\hline Non-manual & 1090 & $4.77 \%$ & 1.00 & 587 & $10.37 \%$ & 1.00 & 502 & $12.33 \%$ & 1.00 \\
\hline Manual skilled/semiskilled & 3840 & $7.41 \%$ & $1.62(1.20-2.17)$ & 1587 & $13.51 \%$ & $1.30(1.00-1.70)$ & 1101 & $12.34 \%$ & $1.00(0.76-1.33)$ \\
\hline Manual unskilled & 1609 & $8.89 \%$ & $1.85(1.36-2.56)$ & 527 & $14.20 \%$ & $1.37(1.00-1.88)$ & 770 & $13.08 \%$ & $1.06(0.79-1.43)$ \\
\hline Marital status & & & * & & & **** & & & NS \\
\hline Married & 5552 & $6.59 \%$ & 1.00 & 1675 & $11.61 \%$ & 1.00 & 704 & $10.65 \%$ & 1.00 \\
\hline Cohabiting & 661 & $10.42 \%$ & $1.58(1.24-2.02)$ & 700 & $15.53 \%$ & $1.34(1.08-1.66)$ & 1143 & $12.74 \%$ & $1.20(0.92-1.55)$ \\
\hline Without a companion & 459 & $11.40 \%$ & $1.73(1.32-2.28)$ & 346 & $14.70 \%$ & $1.27(0.95-1.68)$ & 591 & $14.86 \%$ & $1.40(1.05-1.86)$ \\
\hline \multicolumn{2}{|c|}{ Family income (in minimum wages) } & & * & & & NS & & & ** \\
\hline$>3$ & 2162 & $4.76 \%$ & 1.00 & 1179 & $11.60 \%$ & 1.00 & 772 & $13.47 \%$ & 1.00 \\
\hline$>1$ to 3 & 2021 & $7.72 \%$ & $1.62(1.27-2.06)$ & 593 & $14.12 \%$ & $1.22(0.94-1.57)$ & 718 & $9.19 \%$ & $0.68(0.51-0.91)$ \\
\hline Up to 1 & 1242 & $9.19 \%$ & $1.93(1.49-2.49)$ & 237 & $13.87 \%$ & $1.20(0.84-1.70)$ & 786 & $13.80 \%$ & $1.02(0.80-1.31)$ \\
\hline Missing & 1322 & $8.99 \%$ & $1.89(1.46-2.43)$ & 830 & $12.98 \%$ & $1.12(0.88-1.42)$ & 163 & $18.40 \%$ & $1.37(0.94-1.98)$ \\
\hline
\end{tabular}

aTotals for some variables may differ because of missing values. $\mathrm{RR}=$ relative risk; $95 \% \mathrm{Cl}=$ confidence interval at $95 \%$.

${ }^{*} \mathrm{P}<0.001,{ }^{* *} \mathrm{P}<0.01$, and ${ }^{* * *} \mathrm{P}<0.05$ for the likelihood ratio test. $\mathrm{NS}=$ not significant. 
Table 4. Small for gestational age (SGA) birth rate according to socioeconomic variables in three Brazilian birth cohorts [Ribeirão Preto (1978/79), Ribeirão Preto (1994), São Luís (1997/98)].

\begin{tabular}{|c|c|c|c|c|c|c|c|c|c|}
\hline \multirow[t]{2}{*}{ Variables ${ }^{a}$} & \multicolumn{3}{|c|}{ Ribeirão Preto (1978/79) } & \multicolumn{3}{|c|}{ Ribeirão Preto (1994) } & \multicolumn{3}{|c|}{ São Luís (1997/98) } \\
\hline & $\mathrm{N}$ & $\% S G A$ & $\mathrm{RR}(95 \% \mathrm{Cl})$ & $\mathrm{N}$ & \%SGA & $\mathrm{RR}(95 \% \mathrm{Cl})$ & $\mathrm{N}$ & $\% S G A$ & $\mathrm{RR}(95 \% \mathrm{Cl})$ \\
\hline Paternal schooling (years) & & & * & & & * & & & NS \\
\hline$\geq 12$ & 853 & $7.03 \%$ & 1.00 & 333 & $5.41 \%$ & 1.00 & 163 & $9.82 \%$ & 1.00 \\
\hline 9 to 11 & 667 & $8.85 \%$ & $1.26(0.89-1.78)$ & 595 & $9.41 \%$ & $1.74(1.04-2.91)$ & 835 & $12.10 \%$ & $1.23(0.75-2.03)$ \\
\hline 5 to 8 & 1382 & $11.26 \%$ & $1.60(1.20-2.13)$ & 891 & $14.14 \%$ & $2.62(1.62-4.22)$ & 724 & $13.12 \%$ & $1.34(0.81-2.21)$ \\
\hline 0 to 4 & 2766 & $11.43 \%$ & $1.63(1.24-2.12)$ & 542 & $15.50 \%$ & $2.87(1.76-4.68)$ & 331 & $16.01 \%$ & $1.63(0.96-2.76)$ \\
\hline Maternal schooling (years) & & & * & & & * & & & NS \\
\hline$\geq 12$ & 660 & $7.06 \%$ & 1.00 & 368 & $6.25 \%$ & 1.00 & 119 & $7.56 \%$ & 1.00 \\
\hline 9 to 11 & 880 & $8.87 \%$ & $1.26(0.89-1.79)$ & 610 & $10.49 \%$ & $1.68(1.06-2.66)$ & 861 & $11.96 \%$ & $1.58(0.82-3.04)$ \\
\hline 5 to 8 & 1658 & $10.89 \%$ & $1.54(1.13-2.11)$ & 1039 & $12.99 \%$ & $2.08(1.36-3.18)$ & 1035 & $14.20 \%$ & $1.88(0.98-3.58)$ \\
\hline 0 to 4 & 3350 & $11.94 \%$ & $1.69(1.26-2.27)$ & 631 & $17.27 \%$ & $2.76(1.80-4.25)$ & 418 & $15.31 \%$ & $2.02(1.04-3.95)$ \\
\hline Occupation & & & * & & & ** & & & NS \\
\hline Non-manual & 1090 & $7.25 \%$ & 1.00 & 587 & $9.03 \%$ & 1.00 & 502 & $11.35 \%$ & 1.00 \\
\hline Manual skilled/semiskilled & 3840 & $10.68 \%$ & $1.47(1.16-1.87)$ & 1587 & $12.92 \%$ & $1.43(1.07-1.91)$ & 1101 & $12.72 \%$ & $1.12(0.84-1.50)$ \\
\hline Manual unskilled & 1609 & $13.36 \%$ & $1.84(1.42-2.39)$ & 527 & $16.13 \%$ & $1.79(1.29-2.47)$ & 770 & $14.81 \%$ & $1.30(0.97-1.76)$ \\
\hline Marital status & & & * & & & ** & & & NS \\
\hline Married & 5552 & $9.97 \%$ & 1.00 & 1675 & $10.93 \%$ & 1.00 & 704 & $11.36 \%$ & 1.00 \\
\hline Cohabiting & 661 & $15.58 \%$ & $1.56(1.29-1.90)$ & 700 & $15.71 \%$ & $1.44(1.15-1.79)$ & 1143 & $13.82 \%$ & $1.22(0.95-1.57)$ \\
\hline Without a companion & 459 & $14.35 \%$ & $1.44(1.13-1.83)$ & 346 & $15.61 \%$ & $1.43(1.08-1.89)$ & 591 & $14.55 \%$ & $1.28(0.96-1.70)$ \\
\hline \multicolumn{2}{|c|}{ Family income (in minimum wages) } & & * & & & *** & & & *** \\
\hline$>3$ & 2162 & $7.69 \%$ & 1.00 & 1179 & $11.20 \%$ & 1.00 & 772 & $10.62 \%$ & 1.00 \\
\hline$>1$ to 3 & 2021 & $11.88 \%$ & $1.55(1.28-1.87)$ & 593 & $14.50 \%$ & $1.30(1.01-1.67)$ & 718 & $12.81 \%$ & $1.21(0.91-1.60)$ \\
\hline Up to 1 & 1242 & $14.12 \%$ & $1.84(1.50-2.25)$ & 237 & $16.88 \%$ & $1.51(1.09-2.09)$ & 786 & $15.65 \%$ & $1.47(1.13-1.91)$ \\
\hline Missing & 1322 & $10.85 \%$ & $1.41(1.14-1.75)$ & 830 & $11.57 \%$ & $1.03(0.81-1.32)$ & 163 & $16.56 \%$ & $1.56(1.04-2.33)$ \\
\hline
\end{tabular}


perinatal health indicators analyzed, the evolution of social inequality did not occur in the same manner for each indicator. There was a reduction or disappearance of social inequality regarding LBW and PTB due to a more marked deterioration of these indicators in the more privileged groups, but social inequality measured according to maternal schooling in relation to IUGR increased.

The LBW rate showed an increasing course in Ribeirão Preto from 1978/79 to 1994. The explanation for this increase has been shown in other studies and is based on the increase in PTB rates $(23,24)$. This increase may be due to scientific and technological development, which has permitted better fetal viability and earlier medical interventions during pregnancy, especially unnecessary elective cesarean sections (with no scientific evidence of maternal or fetal benefits) (12).

Social inequality regarding LBW rate was also observed in other Brazilian towns such as Rio de Janeiro and Pelotas (2,3). In the present study, the association of lower maternal schooling and family income with a higher LBW rate was reduced but remained statistically significant. Our hypothesis to explain this reduction is that a reduction in stillbirths and a better detection and management of obstetrical disease is occurring in all socioeconomic strata. The increase in medical interventions with evidence of benefits for maternal-fetal health occurred in a more rapid manner among the more socioeconomically privileged strata (12,23-25) and contributed to reducing the association between socioeconomic situation and LBW along time. On the other hand, in the wealthier group there was a more intense reduction of smoking habit during pregnancy and of other risk factors for LBW than in the less privileged strata (data not shown), a fact that may contribute to explaining the persistence of the association. Goldani et al. (26) reported a reduction of the percentage of smoking pregnant women from 28.9 to $21.0 \%$ between the two periods in Ribeirão Preto, a reduction that, historically, is occurring in a more intense manner in the population with higher educational level and purchasing power $(27,28)$.

As mentioned earlier, the PTB rate increased. However, there was a loss of significance in the association between socioeconomic variables and PTB, with inequality persisting with respect to marital status. This seems to be explained by the more accelerated increase in necessary and unnecessary medical interventions, especially cesarean sections among the more socioeconomically privileged strata $(23,24)$.

SGA rates increased in Ribeirão Preto from 1978/79 to 1994. An explanation for this occurrence appears to be the development of methods for the diagnosis of IUGR and fetal vitality and suffering, resulting in early medical intervention during pregnancy, in addition to the availability of medical equipment and resources that increase fetal viability. Aragão et al. (21) also showed that the higher IUGR rate in Ribeirão Preto in 1994 was related to improved care since it was associated with better obstetrical and neonatal results and with reduction of infant mortality.

The association of socioeconomic variables with SGA birth continued to be significant from 1978/79 to 1994. Social inequality regarding SGA birth probably increased because medical advances in the detection of IUGR were more accelerated among women with lower schooling, a fact that contributed to increasing social differences in this indicator (21). Another fact that may have contributed to increasing this inequality was the more intense reduction of the smoking habit during pregnancy in the better educated strata (23).

No increase in social inequality regarding SGA births was observed according to family income. Since the percentage of missing income was high in both studies, especially in 1994 (29.2\%), the measurement of inequality according to income was less reliable. 


\section{Social inequality at birth in São Luís}

In 1997, no association was observed in São Luís between LBW and any socioeconomic variable. Silva et al. (29) showed that the rate of cesarean sections was $33.7 \%$ in São Luís and that the risk for this intervention was higher among married mothers with higher schooling, who delivered in private hospitals and who received adequate prenatal care. This may explain, among other reasons, why the socioeconomic variables of the São Luís population were not associated with LBW. The increase in cesarean sections among the more privileged strata contributed to the increase in LBW among them and to the disappearance of social inequality regarding LBW.

In this city there was also no association between socioeconomic variables and PTB. This fact may be explained by greater access to early medical interventions during pregnancy by the more socioeconomically privileged strata (23). A family income between one and three minimum wages (intermediate status) was a protective factor against PTB. This supports the hypothesis that being richer is a risk factor for medical intervention (25).

In this city, SGA births were significantly associated only with family income and marginally associated with maternal schooling. The more privileged socioeconomic strata had greater access to medical technology, a fact that probably led to a more frequent detection of fetal suffering and intervention in this group, contributing to an attenuation of social differences in SGA births (19). Since in this city less privileged groups have access to health services of inferior quality, the impact of these services on the early detection of fetal suffering in the poorer groups with lower schooling was possibly lower than in Ribeirão Preto.

Among the limitations of the present study is the percentage of missing data, which was high for some variables such as family income and gestational age. In an attempt to limit the bias caused by the loss of information about gestational age we used imputation of gestational age. The results were similar when imputed or non-imputed data for gestational age were used. The main strength of the present study lies in the fact that it permits the comparison of socioeconomic inequalities in LBW, PTB and SGA rates between two towns of highly distinct socioeconomic levels, considering that the data were collected in a similar manner. The population studies conducted in São Luís and Ribeirão Preto involved samples representing at least $94 \%$ of the pregnant women in the two cities, a fact that reduces the possible occurrence of selection bias.

The literature shows that there was an accelerated increase in medical intervention, especially due to the increase in cesarean sections in the more privileged groups in Ribeirão Preto $(12,23,24)$. This was probably the main factor explaining the unexpected increase in LBW and PTB rates and the decrease or disappearance of social inequality regarding these perinatal indicators in the two cities (30).

\section{References}

1. Waterston T, Alperstein G, Stewart BS. Social capital: a key factor in child health inequalities. Arch Dis Child 2004; 89: 456-459.

2. Andrade CL, Szwarcwald CL, Gama SG, Leal MC. Socioeconomic inequalities and low birth weight and perinatal mortality in Rio de Janeiro, Brazil. Cad Saúde Pública 2004; 20 (Suppl 1): S44-S51.

3. Horta BL, Barros FC, Halpern R, Victora CG. Baixo peso ao nascer em duas coortes de base populacional no Sul do Brasil. Cad Saúde
Pública 1996; 12 (Suppl 1): S27-S31.

4. Kramer MS, Seguin L, Lydon J, Goulet L. Socio-economic disparities in pregnancy outcome: why do the poor fare so poorly? Paediatr Perinat Epidemiol 2000; 14: 194-210.

5. de Almeida MF, Jorge MH. Small for gestational age: risk factor for neonatal mortality. Rev Saúde Pública 1998; 32: 217-224.

6. Koupilova I, Vagero D, Leon DA, Pikhart H, Prikazsky V, Holcik J, et 
al. Social variation in size at birth and preterm delivery in the Czech Republic and Sweden, 1989-91. Paediatr Perinat Epidemiol 1998. 12: 7-24.

7. Vagero D, Koupilova I, Leon DA, Lithell UB. Social determinants of birthweight, ponderal index and gestational age in Sweden in the 1920s and the 1980s. Acta Paediatr 1999; 88: 445-453.

8. Ericson A, Eriksson M, Kallen B, Zetterstrom R. Secular trends in the effect of socio-economic factors on birth weight and infant survival in Sweden. Scand J Soc Med 1993; 21: 10-16.

9. Koupilova I, Bobak M, Holcik J, Pikhart H, Leon DA. Increasing social variation in birth outcomes in the Czech Republic after 1989. Am J Public Health 1998; 88: 1343-1347.

10. Moser K, Li L, Power C. Social inequalities in low birth weight in England and Wales: trends and implications for future population health. J Epidemiol Community Health 2003; 57: 687-691.

11. Goldani MZ, Benatti R, da Silva AA, Bettiol H, Correa JC, Tietzmann $M$, et al. Narrowing inequalities in infant mortality in Southern Brazil. Rev Saúde Pública 2002; 36: 478-483.

12. Victora CG, Vaughan JP, Barros FC, Silva AC, Tomasi E. Explaining trends in inequalities: evidence from Brazilian child health studies. Lancet 2000; 356: 1093-1098.

13. Barros FC, Victora CG, Barros AJ, Santos IS, Albernaz E, Matijasevich $A$, et al. The challenge of reducing neonatal mortality in middle-income countries: findings from three Brazilian birth cohorts in 1982, 1993, and 2004. Lancet 2005; 365: 847-854.

14. Monteiro CA, Benicio MH, Ortiz LP. Secular trends in birth weight in the city of São Paulo, Brazil (1976-1998). Rev Saúde Pública 2000; 34: 26-40.

15. Mello Jorge MH, Gotlieb SL, Laurenti R. A saúde no Brasil: análise do período 1996 a 1999. Brasília: Ministério da Saúde; 2001.

16. Barbieri MA, Gomes UA, Barros Filho AA, Bettiol H, Almeida LEA, Silva AA. Saúde perinatal em Ribeirão Preto, SP, Brasil: a questão do método. Cad Saúde Pública 1989; 5: 376-387.

17. Tonial SR, Silva AA. Saúde, nutrição e mortalidade infantil no Maranhão. São Luís: UFMA/Secretaria de Estado da Saúde/Unicef; 1997.

18. Bettiol H, Barbieri MA, Gomes UA, Andrea M, Goldani MZ, Ribeiro ER. Perinatal health: methodology and characteristics of the studied population. Rev Saúde Pública 1998; 32: 18-28.

19. de Silva AA, Coimbra LC, da Silva RA, Alves MT, Lamy FF, Carvalho $L Z$, et al. Perinatal health and mother-child health care in the munici- pality of São Luis, Maranhão State, Brazil. Cad Saúde Pública 2001; 17: 1413-1423.

20. Cardoso VC, Simões VMF, Barbieri MA, Silva AAM, Bettiol H, Alves MTSSB, et al. Profile of three Brazilian birth cohort studies in Ribeirão Preto, SP and São Luís, MA. Braz J Med Biol Res 2007; 40: 1165-1176.

21. Aragão VM, Barbieri MA, Silva AA, Bettiol H, Ribeiro VS. Risk factors for intrauterine growth restriction: a comparison between two Brazilian cities. Pediatr Res 2005; 57: 674-679.

22. Williams RL, Creasy RK, Cunningham GC, Hawes WE, Norris FD, Tashiro M. Fetal growth and perinatal viability in California. Obstet Gynecol 1982; 59: 624-632.

23. Silva AA, Barbieri MA, Gomes UA, Bettiol H. Trends in low birth weight: a comparison of two birth cohorts separated by a 15-year interval in Ribeirão Preto, Brazil. Bull World Health Organ 1998; 76: 73-84.

24. Silva AA, Barbieri MA, Bettiol H, Goldani MZ, Rona RJ. Can we explain why Brazilian babies are becoming lighter? Int $\mathrm{J}$ Epidemiol 2004; 33: 821-828.

25. Gomes UA, Silva AA, Bettiol H, Barbieri MA. Risk factors for the increasing caesarean section rate in Southeast Brazil: a comparison of two birth cohorts, 1978-1979 and 1994. Int J Epidemiol 1999; 28: 687-694.

26. Goldani MZ, Bettiol H, Barbieri MA, Tomkins A. Maternal age, social changes, and pregnancy outcome in Ribeirão Preto, southeast Brazil, in 1978-79 and 1994. Cad Saúde Pública 2000; 16: 1041-1047.

27. Galobardes B, Costanza MC, Bernstein MS, Delhumeau C, Morabia A. Trends in risk factors for lifestyle-related diseases by socioeconomic position in Geneva, Switzerland, 1993-2000: health inequalities persist. Am J Public Health 2003; 93: 1302-1309.

28. Jefferis BJ, Power C, Graham H, Manor O. Changing social gradients in cigarette smoking and cessation over two decades of adult follow-up in a British birth cohort. J Public Health 2004; 26: 13-18.

29. Silva AA, Lamy-Filho F, Alves MT, Coimbra LC, Bettiol H, Barbieri MA. Risk factors for low birthweight in north-east Brazil: the role of caesarean section. Paediatr Perinat Epidemiol 2001; 15: 257-264.

30. Silva AA, Bettiol H, Barbieri MA, Pereira MM, Brito LG, Ribeiro VS, et al. Why are the low birthweight rates in Brazil higher in richer than in poorer municipalities? Exploring the epidemiological paradox of low birthweight. Paediatr Perinat Epidemiol 2005; 19: 43-49. 